\title{
Germanica
}

GERMANICA $\quad 12 \mid 1993$

Le Modernisme dans les littératures scandinaves

\section{En höst kommer}

\section{(2) OpenEdition}

1 Journals

Édition électronique

URL : http://journals.openedition.org/germanica/1503

DOI : 10.4000/germanica.1503

ISSN : 2107-0784

Éditeur

Université de Lille

\section{Édition imprimée}

Date de publication : 1 juin 1993

Pagination : 185-198

ISSN : 0984-2632

\section{Référence électronique}

«En höst kommer », Germanica [Online], 12 | 1993, Online erschienen am: 06 Juli 2012, abgerufen am 06 Oktober 2020. URL : http://journals.openedition.org/germanica/1503 ; DOI : https://doi.org/ 10.4000/germanica. 1503

Ce document a été généré automatiquement le 6 octobre 2020.

(c) Tous droits réservés 


\section{En höst kommer} med skarpa silhuetter.

7 I skymningen den dagen kom en man gående förbi banvakts-stugan Tomtebo 178. Genom det öppna fönstret hörde banvakts-hustrun hans steg mot syllarna. Hon sköt gardinen åt sidan och tittade ut. Banvaktshuset låg i en sänka. Förbi gavelfönstret rann en bäck. Om vårarna var bäcken smutsgul och flöt tungt. Om somrarna sinade den. Då var vattnet klart. Man kunde se bottnen. Sedan kom höstarna med sina strida regn. Då rasade dikeskanterna. Och bäcken skummade och hävde sig i tjocka vågor. Vintrar med snö låg den bottenfrusen. Den smälte ihop med fälten. Det var man glad åt. 
Men hon gjorde det aldrig.

Och tågen ven förbi. De stannade aldrig. Aldrig. Och ingen såg åt henne. Hon stod $\mathrm{i}$ skuggan av det mörka vidundret. Ingen vinkade åt henne. Ingen.

Jo, en gång.

Tåget dånade nerför sluttningen. Hon stod hopkrupen vid sta-ketet och väntade. Det mullrade över bäckbron. Sedan var det framme vid henne. Just innan loket svepte förbi, såg hon, hur en arm sträcktes ut ur förarhytten. Någon vinkade. Ja, någon vinkade. Hon blev het av lycka. Hon kom sig inte för med någon-ting. Hon bara stod där. När tagbullret förtonat, stod hon kvar.

Det hände flera dagar. Länge. Varje dag stod hon där skälvande av spänning. Och varje gång fruktade hon; I dag är det slut. Men så sträcktes armen ut. Någon vinkade. Och detta gav henne kraft att leva, tyckte hon. Det höjde henne över vardagens stora och små futtigheter. Hon blev glad. Hon sjöng ibland också. Mannen såg det förundrat. Han fröstod, att ensamheten tog hårt på henne. Det var tre kilometer till närmsta gård. Och nu var hon så glad. Han förstod det inte.

Men en dag var det slut. Hon väntade förgäves en hel vecka.

Sedan åldrades hon i tysthet. Men minnet av den som vinkade levde hos henne. Ja, hon levde av det. En gång ska han komma, tänkte hon, han som vinkade.

Men han kom aldrig.

Och nu var hon vid hosten.

På morgonen var backen täckt av en smutsgul isskorpa. När hon satt foten på den, gick det hål. Vattnet vällde upp, sjukt, varigt. Och dahliorna hade frosten tagit. De var döda allesammans.

Från krönet såg han skenorna störta nerför sluttningen. Först var de glänsande. Därnere blev de svarta. Sedan glänste de till igen på väg uppför nästa sluttning. De försvann i ett blått fjärran. Och långt borta i detta fjärran dök något upp. Det var för litet för att vara ett tåg. Det är nog en banvakt, tänkte han. Med dressin.

Då fick han syn på banvaktsstugan. Den låg i skugga. Dess blå rök avtecknade sig mot den mörka sluttningen. Då tänkte han : Stackars människor. De ar som på botten av en gryta. Kommer de nånsin upp ? Står de här nån gång på krönet ? Eller står de bara där nere?

Sedan blev han praktisk. En banvaktsstuga : Värme. Kaffe. En slant.

Då gick han nerför sluttningen. Han gick långsamt. Fötterna var ömma. Hans steg ekade ut i den klara kvällen. Han hörde det själv. Han försökte gå tystare. Men det lyckades inte.

29 När han kom närmare stugan, försökte han lista ut vad slags folk som bodde där. Det såg snyggt och välordnat ut alltsammans. Runt huset gick ett staket. Spjälorna var röda med vita toppar. Fönstren hade gröna luckor. De stod öppna. Han drog in lukten av kaffe. Just när han tänkte vika av från banan, såg han, hur gardiner sakta gled åt sidan. Någon tittade på honom. Då sträckte han på sig. Han gick fortare. Han såg stelt rakt fram. När han var mitt framför huset, smög han sig till en blick. På en vit skylt ovanför dörrposten läste han : Tomtebo 178. Det var målat med prydliga, röda bokstäver.

Hela tiden kände han ögonen i ryggen. Han höjde blicken och gick mycket fort. Han flydde för dem. 

iväg. De sade ingenting. De st
lyfte ner dressinen från banan.

51 Sedan gick de in. tokigt. upp därnere ! Godafton. tänkt säga någonting, sade ingenting. så... Nå, kom med in nu !

Nej, sade mannen stilla. Kom tillbaka! Ni får inte !

Men namnet hade väckt minnen hos honom.

När banvakten kommit ur kurvan, och järnvägen låg rak framför honom, såg han mycket långt borta något svart, litet. Det måste vara en människa, tänkte han. Då är det nog en luffare. Då måste jag raska på, så att jag hinner hem. Så det inte händer nåt

Han trampade på. Rälsen sjöng under honom. Han kände den sången.

Han stannade ett ögonblick på krönet. Då såg han, att mannen redan gått förbi. Då blev han lugn. Han lät dressinen rulla nerför sluttningen.

Den andre gick mitt i banan. När banvakten kommit nerför halva backen, skrek han : Se

Men mannen bara fortsatte. Banvakten drog åt bromsarna. Det gnällde i hela ekipaget. Sedan stannade det med ett ryck. Mannen bara fortsatte. Ett ögonblick trodde banvakten, att han skulle gå rakt på dressinen. Men så stannade han, log litet och sade :

Det var inget fräckt leende. Och hans ögon var lugna och milda. Och banvakten, som

Mannen sade inte heller någonting. Han gick bara åt sidan, som tänkte han fortsätta.

Men då blev banvakten rädd på allvar. Har ni varit in, sade han.

Nej, sade mannen och log litet igen, det har jag inte.

Då visste inte banvakten, vad han skulle säga. Han tänkte ett ögonblick. Han såg ner i marken. Han var rädd för den andres ögon. Sedan sade han: ska ni följa med in kanske ? Det är långt till nästa by. Det är nästan tre mil.

Men då ljög han. Det var bara några kilometer.

Nej, sade mannen, det ska jag inte. Jag orkar nog.

Men skulle det inte vara gott med litet kaffe, sade banvakten. När man har gått långt

Då blev banvakten förtvivlad. Men han fann ingenting att säga. Han stod och svalde en lång stund. Då passade den andre på att gå.

Da sjönk banvakten ner på dressinen. Bakom honom förtonade den andres steg. Men då förlorade han all besinning. Han rusade upp och skrek : Hallå ! Ni har tappat någonting.

Mannen vände sig om och ropade : Vad då? Han hade en underligt klar röst. Den var genomträngande men inte gäll. Den gick ända in i banvaktens själ. Han ropade : En slant ! En stor slant ! Jaså, sade mannen, behåll den då. Sedan beredde han sig att gå.

Men då skrek banvakten ut all sin förtvivlan : Nej ! Hör ni, kom tillbaka! Ni får inte gå !

Och då vände sig verkligen mannen och kom. Han satte sig på dressinen. Och de rullade iväg. De sade ingenting. De stannade mitt framför huset. De klev av, och banvakten

in. 
Det hade mörknat. De blå skuggorna hade tätnat. Skogarna var ogenomträngliga murar.

I förstugans mörker blev de stående ett Ögonblick. Banvakten viskade : vill ni vänta här ett tag, va ? Jag ska tala med min hustru. Hon är litet, ja, som man säger litet orolig av sej.

Sedan gick han in i köket. Mannen hörde honom tala lågmält med någon. Efter en stund öppnades dörren. Banvakten stod i dörröppningen. Han sade sakta : Nu kan ni komma in. Men bry er inte om henne.

Det var mörkt i köket. De kunde knappt se varandras ansikten. Banvaktshustrun stod vid spisen. När främlingen kom in, vände hon sig om. Hon log litet. Men hon sade ingenting. Hennes ansikte var utpinat. Man kom att tänka på fjällbjörkar. Hela hennes gestalt var så. Men när hon log, såg man, att hon en gång varit ung.

De slog sig ner vid bordet. Hustrun satte fram koppar och fat. Hon rörde sig ljudlöst över golvet. När man minst visste det, stod hon bakom en. Banvakten vred sig oroligt på stolen. Han sökte den andres ögon. Men han mötte dem inte. Främlingen satt tyst. Han stirrade ner i golvet.

De satt länge vid sina tomma koppar, tysta.

Men plötsligt stod banvaktshustrun bakom främlingen. Då såg han upp. Han mötte hennes ögon. De var skrämda, ensamma. När hon hällde i kaffet, darrade hennes händer. Hon dröjde en stund vid hans sida.

Vid kaffet blev banvakten talför. Han sade : Har ni gått långt i dag ?

Jag menar, var kom ni ifrån nu senast, och vart ska ni ta vägen?

Han frågade inte av nyfikenhet. Det var bara for att ha någonting att säga.

Då höjde mannen blicken. Han såg rakt igenom banvakten. Eller åtminstone tyckte han så. Han sade : Jag kommer nånstans ifrån. Jag ska väl nånstans. Vart vet jag inte. Eller jag kanske vet det. Det är mitt liv. Eller mitt öde.

Det var underligt svarat, tyckte banvakten. Åtminstone av en luffare, tänkte han sedan.

Han sade eftertänksamt : Det är nog så. Så att man kommer och går och... ... och går, fast man inte vet... fast man inte vet, ja... vart man går.

5 Sedan trasslade banvakten in sig i sina funderingar. Det blev tyst en lång stund. Hustrun stod mitt på golvet och såg på dem. Det kom ett lyssnande uttryck i hennes ansikte.

6 Då fann banvakten sig själv. Och han sade : Nej, vi kommer och går. Det är precis som tågen. Dom med. Och aldrig kommer dom fram. Dom bara går. Men en gång stannar det väl alltihop. Ja, det ska bli skönt.

Skönt, sade främlingen.

Hans stora, underliga ögon brände igenon banvakten. Skönt. Är ni trött ? Trött på livet. Ni får inte, hör ni ! Ni får inte !

69 Vad får jag inte, sade banvakten. Får jag inte vara trött ? Man blir trött, förstår ni. Dom fröbannade tågen. Ni vet inte, hur det är. Tågen visslar förbi. Dom ser inte åt en. Ja, ibland vet man inte, vad man vill. Man skulle bara vilja försvinna. Springa åt helvete.

Då reste sig främlingen. Först nu såg banvakten, hur stor han var. Ja, han fyllde hela rummet. Och banvakten kände, hur han krympte inför hans blick. Dessa underliga ögon 
Det var ett långt ögonblick av tystnad. Och i tystnaden blev han så liten, banvakten. Ja, han blev ingenting, ingenting.

Då talade mannen. Han fyllde hela rummet, allt, med sin klara röst. Och medan han talade, blev banvaktens hjärta fyllt av djup frid.

Han sade : Har ni hört militärtågen om nätterna ? Jag har hört dem. De mullrar dovare än andra tåg. De fyller nätterna med sin ton. Jag har stått på banvallarna mörka nätter, järnnätter. Jag har sett och lyssnat bara. Vet ni vad jag sett ? Jag har sett människor. Det har jag gjort. Människor. Vet ni vad jag hört ? Jag har hört sånger genom de öppna kupéfönstren. Och musik. Skratt. Då är det lyckligt då, tänker ni. Lyckliga människor sjunger. Men ser ni, när jag står där i mörkret och ser de upplysta vagnarna blixtra förbi, då kommer det för mej så underligt. Och jag ser ingenting längre. Och jag hör ingenting längre. De glada människorna är borta. Skratten är stumma. Kvar är bara rasslet av vagnarna. Och dä ser jag rakt igenom natten. Och vet ni vad jag ser?

Han viskade. Banvakten såg på honom med stora ögon. De blänkte genom mörkret. Banvaktshustrun stod orörlig. Hon knöt händerna och förde dem till hjärtat.

Jag ser rakt genom natten. Mina ögon är skarpare än på dagen. De tränger genom allting. Och då ser jag - Döden. Döden. Hör ni, Döden. Vet ni, varför de är så glada ? De är rädda, förstår ni. De är rädda för Döden. Rädda. Tänk om de lika glatt mötte livet. Men livet är så självklart. Det ar ingenting, som man behöver be om. Och därför är det så värdelöst. Man blir trött. Som ni. Och man vill lägga sej ner och dö. Som ni och alla andra. Och så mördar man sej själv. Hela mänskligheten. Det är det kollektiva självmordet. Kriget. Ja, man dör, när man skulle leva. Leva, hör ni. Leva. Ty man får inte dö. Man måste leva. Och kämpa. Och älska. Kom ihåg att så länge en människa är älskad av bara en annan människa, sa länge måste hon leva. Hon måste. Ty ingen får dö. Ingen. Och en gång när alla människor ska förstå att kärleken är det enda, som ger en kraft att leva, och att livet har skänkt oss alla kärleken, den dagen ska ingen vilja dö mer. Den dagen har den eviga våren kommit.

Då sade banvakten som för sig säjlv : Idag kom hösten. I morse var skenorna frostiga. Alla blommor var frusna.

Nej, sade mannen, än är det långt till hösten. Men den dag när de två sista människorna höja sej ur sina gyttgiga skyttegravar och skrika till varandra : Jag hatar dej! Jag hatar dej! och när dessa två människor i stället för att räcka varandra handen och älska varandra lägga an på varandra med mänsklighetens två sista gevär och då dö, utan att ha älskat eller varit älskade av någon, då har hösten kommit. Men den dagen får aldrig komma, hör ni. Aldrig. Men det beror på er och mej. Vi måste älska livet. Vi måste leva älskande. Och ingen av oss får nånsin tröttna. Vi måste kampa. Och vi får aldrig dö. Ty annars kommer hösten. Och den får inte komma, hör ni. Den far inte komma. Förstår ni nu, varför ni inte får bli trött?

Ja, sade banvakten ödmjukt, nu förstår jag.

Då satte sig mannen stilla. Det blev en lång tystnad. Mörkret lade sig mjukt kring allt. Mannen såg ner i golvet. Men hela tiden kände banvakten hans ögon. De brände. Så sade banvakten lågt : Ja, jag förstår det nu. Man måste leva. Och det kanske är en lycka det, att leva. Man kanske är lycklig, fast man inte vet det. Vi kanske är lyckliga vi alla, jag och min hustru och... 
Då sköt blodet upp i banvaktshustruns ansikte. Hon rusade fram till bordet och slog näven i det, så att kaffekopparna skallrade. Banvaktens kopp föll omkull. Den rullade ner på golvet. Hon trampade på den. Hon stampade sönder den.

Hon skrek : Lycka? Vad vet du om min lycka? Du, som aldrig frågat efter mej! Du som aldrig någonsin sett på mej med en älskandes blick! Du ska tala om lycka! Nej, säger jag dej, vi ska aldrig bli lyckliga. Hör du det ! Aldrig ! Aldrig !

Sedan tystnade hon. Hon liksom sjönk ihop. Hon gick och hämtade sopskyffeln och borsten. Hon sopade upp koppen.

Nej, sade främligen sakta, man vet ingenting om andras lycka.

Men, sade banvakten hjälplöst, en gång så var du lycklig ändå. Du sjöng. Du skrattade. Det var en sommar. Jag minns det nu.

Då kom banvaktshustrun fram till bordet. Hennes kinder glödde. Blodet sprang fram i läpparna. Hennes gestalt fick resning. Hennes stämma blev varm och klar. Hon stod rak och stolt inför dem. I det ögonblicket var hon riktigt vacker. Och ung.

Och i det ögonblicket var det, som om banvakten för första gången såg sin hustru.

Hon sade: Ja, du har rätt. En gång var jag lycklig. Men du vet inte, varför jag var det. Och du får aldrig veta det. Och en gång kanske jag blir lycklig igen. Ja, jag vet, att jag blir det. Ty en gång kommer han. Ja, jag vet det. En gång ska han komma.

Sedan blev hon sig själv igen. Men en lång stund var hon ung.

Nej, sade främlingen sakta, man vet så litet om lyckan. Man vet bara, att en gång måste den komma. Jag vet ingenting om min lycka, fastän jag kanske redan har den. Det kanske är min lycka detta, att vara fri, att komma och gå och inte veta, vart jag kommer till sist. Nu känner jag mej lyckligare än nånsin förr. Ty jag har inte alltid gått så här. Jag har arbetat hårt. Men alltid då var jag så orolig. Till sist stod jag inte ut längre. Jag gav mej iväg. Och nu vet jag, att jag funnit mej själv. Förut, när jag arbetade, ägde jag ju inte mej själv. Det var andra, som rådde om mej. Jag var pa sjön flera år. Nu senast var jag vid järnvägen. Det var en sommar. Det var längesen.

$90 \mathrm{Nu}$ blev banvakten intresserad. Jaså, sade han, ni var vid järnvägen. Då kanske ni känner till den här biten då?

91 Jo men, sade mannen, det gör allt. Jag var eldare här en gång.

Jaha, sade banvakten, då kanske ni kommer ihåg den här stugan med då ?

Jodå, det gör jag. Jag har en särskild anledning att komma ihåg den. Hurså, sade banvakten intresserad.

94 Jo, den sommaren var jag ovan vid arbete. Jag blev lätt trött. Ja, en gång svimmade jag framför fyren. Men då erbjöd sej godsvårdarn att avlösa mej, så att jag kunde vila ett tag. Och vi kom överens om att varje gång, som jag kände mej trött, skulle jag ge tecken åt honom, just när vi passerade banvaktsstugan. Jag skulle sträcka ut armen genom vindrutan och vinka åt honom. På så sätt blev den här stugan ett slags rastställe för mej. Jag välsignade den.

Jaha, sade banvakten stilla.

Han tänkte säga något mer. Men han hann inte.

Hustrun kom före. Hennes röst var hes av dov förtvivlan. Hon sade : Hur längesen var det sen det där hände ? 

möta sitt öde. om våra egna. förstå det.

Ja, sade mannen eftertänksamt, det var nog en tio år sen.

Hon räknade efter i minnet. Jo, det stämde. Då blev hon på en gång mycket gammal. Hon reste sig tungt och gick mot dörren. Hennes ansikte var grått. Hon lämnade dörren öppen. Det var mörkt ute.

Männen såg på varandra. Banvakten sade : Ja, hon blir så där ibland. Bara går ut. Vet ni, då blir jag rädd för henne. Ja, ibland känns det så underligt. Som jag inte skulle kunna stå ut. Jag behöver någon. Men jag har ingen. Och hon pratar så underligt också. Om att

Nej, sade främlingen sakta, vi vet ingenting om andras öden. Vi vet inte ens någonting

Nej, sade banvakten, jag undrar ibland, hur det ska gå med allting. Om vi ska kunna stå emot. Det är så underligt, att det är människor, som ha skapat kriget. Människorna, som ändå är goda. Som man skulle vilja tro på.

Nej, sade mannen stilla,jag tror pä människan, men inte pä människorna.

Det kunde inte banvakten förstå nu. Men en gång, när han blev ensam, skulle han

Efter en stund sade han : Jag får väl gå ut och titta efter henne. Så hon inte gör något tokigt. Man vet aldrig.

Nej, sade främlingen, man vet ingenting.

Så gick banvakten. Hans steg dog bort i mörkret.

Efter en stund dök ljud av steg upp ur detta mörker. Banvaktshustrun stod i dörren. Hon gick långsamt fram till den ensamme vid bordet. Trots mörkret såg han, att hon var upprörd. Hennes hår var i oordning. Hon andades oroligt. Hennes röst lät trött, när hon talade. Hela hennes gestalt var tyngd av djup förtvivlan. Hon sade : Jag sade nyss, att jag en gång skulle bli lycklig. Att han en gång skulle komma. Nu vet jag, att det inte är sant. Jag blir aldrig lycklig.

Varför inte, sade främlingen.

En sommar var jag lycklig. Jag var glad som aldrig förr. Ni vet inte varför, men jag ska säga er det. En gång, när jag stod vid staketet och väntade på ingenting, rusade ett tåg förbi. Just när loket var mitt framför mej, sträcktes en arm ut genom vindrutan. Någon vinkar, tänkte jag. Och då kände jag mej så lycklig. Jag väntade varje dag. En dag väntade jag förgäves. Jag blev bitter. Men så tänkte jag: En dag ska han komma i alla fall, han, som vinkade. Jag behöver inte vänta förgäves.

Men nu vet jag det : jag har väntat förgäves.

Nej, sade mannen sakta, ni har inte gjort det. Jag är ju här. Varför är ni då så olycklig ?

Men det var ju inte åt mej ni vinkade, sade banvaktshustrun. Det var ju åt en annan.

Nej, sade mannen ömt, det var ju åt er. Men jag ville inte säga det, när han var inne.

Men hon hörde på honom, att han ljög. Hon sade stilla : Men nu när ni har kommit, vill jag i alla fall se på er.

Hon gick fram till väggen och tände ljuset. Mannen reste sig och gick henne till mötes. Hon smög sig tätt intill honom. Hon granskade varje drag i hans ansikte. Hennes händer gled genom hans hår. Nu när ni i alla fall har kommit, säg, vill ni ta mej med ?

Nej, sade mannen, det kan jag inte. 
Men varför?

Men varför? inpå henne.

Jag kan inte säga det. Jag vet bara, att jag inte kan.

Men säg mej då, vem ni är.

Ja, sade främlingen, jag är Människan.

Då såg hon på honom med glänsande ögon. Hon slog armarna om honom och kysste honom länge. Sedan sade hon : Säg nu, att ni vill ta mej med !

Nej, sade han, jag kan det inte.

Det är väl en lycka det också, sade mannen sakta, att kunna bära sitt öde.

Då sade inte banvaktshustrun något mer. Hon sjönk ner på en stol, lutade huvudet i armarna och grät sakta.

Då kom någon därute. Det var banvakten. Han stannade villrådig i dörröppningen. Men så fick han syn på hustrun. Då satte han sig på en stol och såg rakt ut i rummet. Han undvek främlingens ögon. Och främlingen undvek honom. Ljuset fjärmade dem från varandra. Det var tyst länge.

Så reste sig mannen. Och han talade med sin klara röst, som gick in i allas hjärtan. Han sade : Tack för den godhet, som ni visat en gammal man.

Då såg banvakten upp, och han fann, att mannen var mycket gammal.

Så sade han : Tack och farväl.

Sedan gick han med stadiga steg mot dörren. Han stängde den sakta efter sig. Hans steg hördes länge. Efter en stund kom han tillbaka. De hörde honom treva efter dörrvredet. Så öppnades dörren. De hörde hans klara röst. Han sade : Det goda segrar alltid! Annars fanns inte världen till!

2 Sedan sköt han igen dörren. Hans steg dog bort. Efter en stund reste de sig och gick ut på banan. De stod där länge utan att säga någonting. Sedan gick banvaktshustrun in. Banvakten följde efter. När hon kommit in, kastade hon sig omkull på golvet och grät. Hennes spetsiga skuldror höjdes och sänktes. Hon sparkade i golvet. Banvakten stod en stund hjälplös. Sedan tog han på sig mösssan och gick ut. Han gick sakta uppför sluttningen. Ibland sparkade han till en sten. Han visslade tankspritt.

Han tänkte väl på någonting.

När mannen gått, blev hon lugnare. Hon låg en stund stilla på golvet. Sedan reste hon sig och gick ut. Hon ställde sig mitt på banan.

Mörkret smög sig tätt intill henne. Ingen skulle kunna se henne, förrän han var alldeles

Hon tänkte tankar om att stå kvar. Att möta sitt öde.

Fem kilometer norr om banvaktsstugan Tomtebo 178 passerade järnvägen en stor mosse. Tågen gick över den med sakta fart. Den hade falsk botten. Där mossen slutade, gjorde järnvägen en skarp svängning.

När de passerat mossen och gick in i kurvan, infångades en man mellan lokets ljuskoner. Föraren fick se honom för sent. Han bromsade. Tågsättet darrade. Just innan de körde på honom, vände han sig och såg rakt in i lyktorna. Sedan stötte loket till honom. Han flög ut i luften och försvann ur ljuskretsen. Han blev aldrig överkörd. 
Ögonblicket därefter var föraren nere på banan. Godsvårdaren kom springande. Långt nerifrån tåget kom konduktören. Passagerarna gick ut på plattformarna. Strömavbrott, skrek konduktören. Då lugnade de sig. De hade varit oroliga. De gick in. I militärvagnarna längst ner i tåget spelade man dragspel. Nån sjöng också.

Föraren var vit i ansiktet. Han lutade sig tungt mot loket. Han måste gripa tag i konduktören för att inte falla. Sedan gick de in i ljuskretsen. Han ligger nog där nere, sade föraren sakta. Konduktören lyste nerför banvallen.

Vid sammanstötningen slungades han i en vid båge snett ut. Vid nedslaget slog han huvudet $\mathrm{i}$ en sten. Han dog ögonblickligen.

De såg honom inte med detsamma. Han smälte ihop med marken. Konduktören var den förste. Han hasade nerför banvallen. De andra kom efter. Konkuktören lyste på honom. Han låg på rygg. De hjälptes åt att vända upp honom. Konduktören lyste på hans ansikte. Han log ännu i döden. Ögonen var slutna. De förstod, att han var död. Blodet forsade ur ett sår i pannan. Det hade färgat marken.

Då vände sig föraren bort. Han sade sakta : Det var den andra i dag.

Sedan började han gråta. Han skakade i snyftningar.

Gråt inte, sade konduktören milt. Det är väl inte ditt fel heller. Du kan väl inte hjälpa, att folk går i vägen för tåget.

Då sade lokföraren med rösten full av gråt : Det är så ohyggligt alltihop. Ni, som inte varit med om det, kan inte förstå det, Ni hörde inte, hur hon skrek, innan jag körde över henne. Men jag hörde det. Åh, det var ohyggligt, med den där banvaktshustrun. Men att han tog det så lugnt, banvakten. Vi bar in henne i köket, det som var kvar. Vi lade henne på bordet. Han ville ha henne hos sig i natt, sade han. Sedan bredde han ett lakan över. Men att han tog det så lugnt, så självklart. Det var ju ändå hans hustru.

7 Då sade konduktören stilla: Vi känner inte människornas vägar. Men ser du inte, så lyckligt han 1er. Det kanske var en lycka för honom att få dö, förstår du, kanske för henne också. Vi vet ingenting.

8 Sedan stod de tysta en lång stund, de tre männen kring den döde. De hörde varandra andas. De hörde dragspelsmusiken slå över i ljusaste dur. Den växte i vinden. Man skrattade långt där nere. Man sjöng också.

9 Medan de tre männen stod där, kom regnet. Det ven till. Vinden pressade på. Den växte till storm. På några sekunder var de genomblöta.

o Då böjde sig konduktören ner över den döde. Han sade liksom för sig själv : kände honom. De kallade honom Ville på Śne. Det var för att allt gick tokigt för honom. Han var alltid titet underlig. Men så när hustrun gick ifrån honom, blev han tokig. Han for omkring i bygderna och höll möten. Sedan lugnade han sig. Men han kunde aldrig arbeta. Han gick omkring på vägarna. Till slut tog de in honom på ålderdomshemmet. Han var tokig, sade man. Men han var väl inte tokigare han än andra. Men han kunde inte vara där heller. På vårarna stack han iväg. Men varje höst kom han tillbaka. Då gick han alltid banan till ålderdoms-hemmet.

1 Sedan rätade konduktören på sig och tog av sig mössan. Regnet rann av honom. De andra väntade otåligt. Mörkret var ännu tätare. Loklyktorna blev sudiga fläckar. Allt förlorade sina konturer.

Konkuktören sade sakta : Tack för det du gav mej en gång. Du kom om hösten. Då är det väl höst nu då. 
153 Tågsättet kved och knakade. Regnet spolade över plattformarna. Det smattrade mot taken. Och i de ljusa kupéerna kröp människorna ihop och talade lågmålt om ingenting. I restaurangvagnen var det tyst. Ingen slamrade med tallrikar. Ingen pratade. Och i militårvagnen dog dragspelet i en djup suck, tyckte man.

154 Och medan de stod där i mörkret vid en okänd station, och regnet slog mot fönsterrutorna, så kände alla i detta tåg, ja, de visste det, att nu var hösten här. Och de kröp ihop i sina varma vagnar. De satt tysta. En del frös.

Och stormen ven. Mörkret lurade tätt utanför.

Och i mörkret gick hösten fram förbi ett ensamt tåg på linjen.

157 Sedan bar de in honom i en tom kupé.

158 SLUT. 